\title{
Adipose inflammation: cause or consequence of obesity-related insulin resistance
}

\author{
Ping Jiao \\ Haiyan $\mathrm{Xu}$ \\ Hallett Center for Diabetes \\ and Endocrinology, Brown Medical \\ School, Providence, RI, USA
}

\begin{abstract}
Obesity constitutes a critical risk factor for the development of many life threatening diseases, particularly insulin resistance and type 2 diabetes. Adipose tissue plays an important role in regulating whole body energy homeostatsis and obesity-related insulin resistance. Inflammation has been commonly linked to insulin resistance. Recent studies demonstrated that adipose tissue is an important source for producing inflammatory molecules in the obese state, primarily due to accumulation of macrophages. Animal models deficient in key inflammatory molecules or with reduced adipose macrophage infiltration are protected from development of obesity-related insulin resistance. Repression of adipose inflammation may be a useful approach to ameliorate obesity-associated metabolic disorders.
\end{abstract}

Keywords: adipose inflammation, insulin resistance, obesity

\section{Correlation between obesity-related insulin resistance and inflammation}

Approximately $30 \%$ of US adults and $20 \%$ of school-aged children are obese. Obesity has become an epidemic disease and its incidence is still rapidly increasing at an alarming rate (Hill et al 2003). The hallmark of obesity is manifested by massive expansion of adipose tissue, attributable to excessive food consumption and sedentary life style in modern society. Obesity has been identified as a major risk factor for the development of many life-threatening diseases, such as hypertension, atherosclerosis, dyslipidemia, and particularly type 2 diabetes (Kopelman 2000). Type 2 diabetes itself is also a risk factor for the development of heart disease and stroke. As a matter of fact, more than $65 \%$ of people with diabetes die from heart disease or stroke. The underlying molecular mechanism for obesity-related metabolic disorders is still not well understood. The correlation between obesity, diabetes and inflammation have been observed as early as several decades ago, when increased circulating levels of acute phase proteins, such as fibrinogen, haptoglobin, and $\alpha-1$ antitripsin, were reported (Fearnley et al 1959; Ogston and McAndrew 1964; Ganrot et al 1967). In more recent studies, elevated serum concentrations of more acute phase proteins were shown, including sialic acid, $\alpha-1$ acid glycoprotein, C-reactive protein (CRP) and serum amyloid A (Crook et al 1993; Pickup et al 1997). In addition, inflammatory proteins such as IL-6 and plasminogen activator inhibitor 1 (PAI-1), as well as increased white cell count are also found to correlate with type 2 diabetes (Festa et al 2002; Pradhan et al 2001; Vozarova et al 2002). However, findings from these human population studies alone were not sufficient to stimulate thoughts regarding whether inflammation could be a causative factor for the pathogenesis of obesity-related insulin resistance and type 2 diabetes.

Recent studies indicate that inflammatory event in the adipose tissue may play a critical role in the development of insulin resistance. Tumor necrosis factor- $\alpha$ $(\mathrm{TNF} \alpha)$ is the first cytokine identified with elevated expression in adipose tissue from obese rodents and humans, resulting from both increased production and abnormal 
processing (Hotamisligil et al 1993, 1995; Xu et al 2002b). $\mathrm{TNF} \alpha$ inhibits signaling from the insulin receptor and neutralization of TNF $\alpha$ by infusion with a tumor necrosis factor receptor-immunoglobin G (TNFR-IgG) chimeric protein improves insulin sensitivity (Feinstein et al 1993; Hotamisligil et al 1993, 1994). TNF $\alpha$ can also cause dysregulated lipolysis in adipocytes, therefore potentially contributes to the elevation of circulating free fatty acid (FFA) concentration (Green et al 1994). FFA has been demonstrated to be a critical factor for causing systemic insulin resistance in multiple tissues, such as liver and muscle. The discovery that inflammatory cytokine TNF $\alpha$ impairs insulin signaling greatly stimulated the field and scientists started to view that inflammation may be a causative event for the pathogenesis of obesity-related insulin resistance. Subsequently, more cytokines, chemokines and other secretary proteins are found to increase in adipose tissue of obese rodents and/or humans, including leptin, interleukin-6 (IL-6), IL-8, monocyte chemotactic factor 1 (MCP-1), angiotensinogen, visfatin, resistin, retinol-binding protein-4, serum amyloid A (SAA). Among these molecules, IL-6, IL-8, and MCP-1 have been reported to impair insulin action (Rotter et al 2003; Sartipy and Loskutoff 2003). The reason that cytokine and chemokine production increases in response to triglyceride accumulation in adipose tissue is not clear. One possibility is that these factors might have designated roles to limit excessive fat mass expansion, which unfortunately is at the cost of inducing insulin resistance. Consistent with this hypothesis, TNF $\alpha$, IL-8, and MCP-1 have been reported to inhibit adipocyte differentiation (Xu et al 1999; Gerhardt et al 2001; Xu and Hotamisligil 2001). Animals deficient in CCR2, the major receptor of MCP-1, have larger adipocytes but are more insulin sensitive (Weisberg et al 2006). This hypothesis is further supported by two animal models: adipose tissue TNF $\alpha$ transgenic and fat-specific insulin receptor knockout mice. Both models demonstrated reduced adiposity but accompanied by severely impaired insulin signaling in adipose tissue (Bluher et al 2002; Xu et al 2002a). However, the systemic insulin sensitivity has been improved despite adipose insulin resistance, suggesting the importance of overall fat mass on metabolism.

\section{Animal models deficient in key inflammatory molecules}

Intensive investigations with various animal models deficient in key molecules in the inflammatory pathway further provided solid evidence for the causative role of inflammation in the development of obesity-related insulin resistance.
The first proof of principle animal model is TNF $\alpha$-deficient mice. In the absence of TNF $\alpha$, mice are partially protected from development of hyperlipidymia, hyperglycemia and hyperinsulinemia without an effect on body weight in obesity models induced by high fat diet, deficiency of leptin, or gold-thioglucose injection (Uysal et al 1997; Ventre et al 1997). Increased tyrosine phosphorylation of insulin receptor was observed in both adipose tissue and muscle in obese mice deficient in TNF $\alpha$. In addition, KB-R7785, a synthetic compound that inhibits TNF $\alpha$ production, can improve insulin sensitivity in obese/diabetic KKA ${ }^{y}$ mice (Morimoto et al 1997). These in vivo data support a role of TNF $\alpha$ as a candidate mediator of obesity-induced insulin resistance but also indicate the involvement of other factors since the protection is partial. TNF $\alpha$ signals through two receptors, $\mathrm{p} 55$ and $\mathrm{p} 75$. The role of TNF $\alpha$ receptors in mediating the effect of TNF $\alpha$ on obesity-related insulin resistance is controversial in two independent studies, which might be attributable to differences in genetic backgrounds (Schreyer et al 1998; Uysal et al 1998).

Recently, the c-Jun NH2-terminal kinase (JNK) has appeared as a vital regulator in obesity and insulin resistance. Both TNF $\alpha$ and FFA are potent stimulators for JNK activation. Indeed, JNK activity is elevated in liver, adipose tissue and muscle in both diet-induced obese mice and $o b / o b$ mice (Hirosumi et al 2002). Interestingly, different JNK isoforms seem to play distinct roles. JNK1 deficient mice have decreased adiposity and adipocyte size, increased serum adiponection and lowered serum resistin concentrations, lowered glucose and insulin concentrations, enhanced insulin signaling in the liver and improved whole body insulin sensitivity upon high fat diet (Hirosumi et al 2002). Absence of JNK1 also partially protected $o b / o b$ mice from developing hyperglycemia and hyperinsulinemia (Hirosumi et al 2002). In contrast, deficiency of JNK2 does not have any influence on diet-induced insulin resistance. These results demonstrate that JNK1 accounts for the majority of increased JNK activity in insulin target tissues and is an important regulator in obesity-related insulin resistance.

IKK $\beta$, the master regulator of inflammation which can also be activated by TNF $\alpha$ and FFA, is another important serine kinase involved in the development of obesity-related insulin resistance. Homozygous IKK $\beta$ deficiency is lethal due to increased liver apoptosis but heterozygous IKK $\beta^{+/-}$mice appear normal. Lowered fasting glucose and insulin concentrations were observed in IKK $\beta^{+/-}$mice on both standard diet and high-fat diet compared to wild-type littermates (Yuan et al 2001). Furthermore, absence of one IKK $\beta$ allele is sufficient 
to lower blood glucose and plasma FFA levels as well as improve glucose tolerance in $o b / o b$ mice (Yuan et al 2001). Arkan and colleagues (2005) further selectively deleted IKK $\beta$ in hepatocytes or myeloid cells and showed that IKK $\beta$ deficiency in hepatocytes locally protected liver from development of obesity-related insulin resistance, but fat and muscle still develop insulin resistance upon high fat diet. Consistent with these results, transgenic mice selectively expressing the constitutively active form of IKK $\beta$ in the liver have increased hepatic production of proinflammatory cytokines, which caused profound hepatic insulin resistance (Cai et al 2005). In addition, these proinflammatory cytokines also cross talk with other tissues and lead to hyperglycemia, and modest systemic insulin resistance (Cai et al 2005). Interestingly, specific deletion of IKK $\beta$ in myeloid cells of diet-induced obese mice or $o b / o b$ mice is sufficient to improve systemic insulin sensitivity, which is attributable to decreased production of proinflammatory cytokines or chemokines that are known to inhibit insulin signaling in cultured cells (Arkan et al 2005). These data demonstrate that IKK $\beta$ plays an important role in the development of obesity-related insulin resistance by acting in multiple cell types, particularly myeloid cells.

TLR4, a family member of toll-like receptors (TLRs), plays a critical role in pattern recognition and activation of innate immunity (Medzhitov et al 1997). Lipopolysaccharide (LPS) is the well characterized ligand for TLR4 (Poltorak et al 1998). Several recent studies demonstrate that FFAs, whose levels are elevated in obesity, can also activate TLR4 (Lee et al 2001). Deficiency of TLR4 can prevent FFA-induced production of inflammatory cytokines in both macrophages and adipocytes. In lipid-infused animals, absence of TLR4 significantly improved insulin signaling in muscle and decreased production of inflammatory cytokines in adipose tissue (Shi et al 2006). Absence of TLR4 also modestly improved systemic insulin sensitivity in female mice upon high fat challenge, presumably through reduced production of proinflammatory cytokines in liver and adipose tissue. Similar phenotypes are also observed in diet-induced obese mice with a loss-of-function mutation in TLR4, confirming a role of TLR4 in linking innate immunity and lipid-induced insulin resistance (Tsukumo et al 2007).

\section{Adipose tissue macrophage accumulation in obesity}

Despite the substantive amount of data demonstrating the link between inflammation and obesity-related insulin resistance, the specific cell source for production of inflammatory molecules are unclear though it appears to be originated from

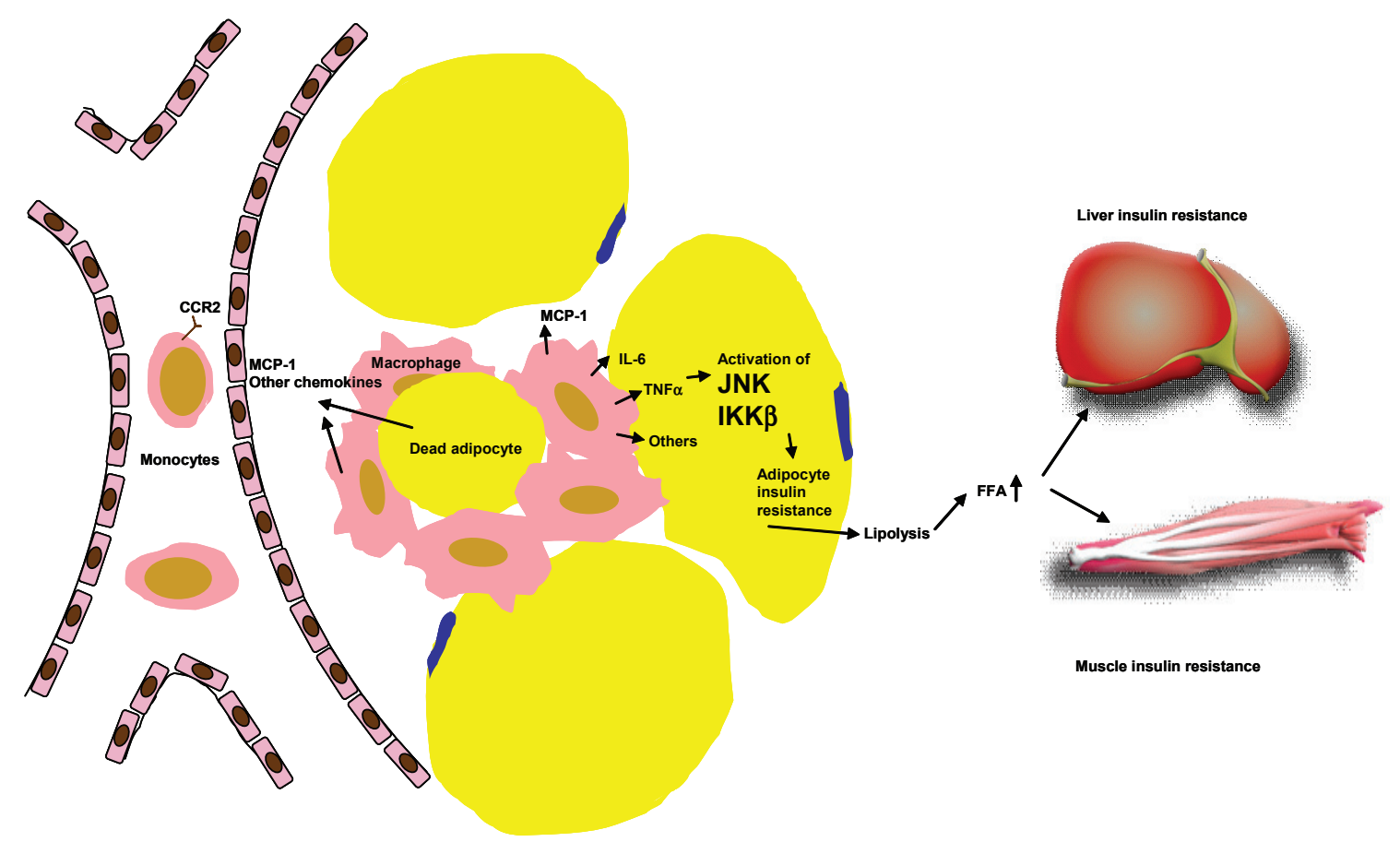

Figure I Mechanism of adipose macrophage infiltration and the role of adipose inflammation in systemic insulin resistance. Accumulation of triglycerides in adipocytes causes increased production of MCP-I and the other monocyte chemotactic factors, which attract circulating monocytes to migrate into adipose tissue. These inflamed monocytes mature into classically activated macrophages and secrete a variety of proinflammatory factors that can impair insulin signaling in adipocytes. Dysregulated adipocyte lipolysis contributes to elevation of circulating FFA level which subsequently induces insulin resistance in other tissues such as liver and muscle. 
adipose tissue. It was originally thought that adipocytes are the cell type that produces proinflammatory factors. It has been shown that adipocytes possess many features of immune cells and adipocyte precursors have phagocytic capacity and can be converted into macrophage-like cells in response to certain stimuli (Cousin et al 1999; Charriere et al 2003). Two studies in 2003, which used transcription profiling approach to compare adipose tissue from lean and several rodent obesity models, or adipose tissue from obese animals before and after treatment with compounds of the thiazolidinedione class of anti-diabetic agents, have showed that the majority of genes significantly upregulated in obese adipose tissue are macrophage and inflammatory genes, which can be repressed by rosiglitazone (Weisberg et al 2003; Xu et al 2003). By separating adipocytes from stromal-vascular cells and histological examination, these studies revealed massive macrophage accumulation in adipose tissue in the obese state. Bone marrow transplant study further demonstrated that these macrophages are predominantly infiltrated, rather than converted from local preadipocytes. Activated macrophages are known to secrete a variety of pro-inflammatory cytokines and chemokines. In these two studies, isolated stromal-vascular cells, the fraction containing infiltrated macrophages, are demonstrated to be the predominant source for producing proinflammatory molecules in comparison to adipocytes, including TNF $\alpha$, MCP-1, IKK $\beta$, IL-1 $\beta$, and inducible nitric oxide synthase (iNOS). These results suggest that infiltrated macrophages in adipose tissue in state of obesity are likely an important source contributing to elevation of circulating inflammatory marker proteins. Blood mononuclear cells (MNCs) in the obese state are also reported to be in a proinflammatory state, as reflected by increased nuclear factor kappa-B $(\mathrm{NF}-\kappa \mathrm{B})$ binding activity, decreased $\mathrm{I} \kappa \mathrm{B}$ content and increased transcription of NF- $\kappa \mathrm{B}$ controlled proinflammatory genes, indicating that inflamed circulating MNCs may also contribute to elevation of circulating inflammatory marker proteins as well (Ghanim et al 2004).

The triggering factors for macrophage infiltration into adipose tissue and the roles of infiltrating macrophages are still not well understood. One speculation is that enlargement of fat cells, which commonly occurs in obese state at relatively early stage, may trigger the initial secretion of critical monocyte chemotactic factors. Once macrophages infiltrate into adipose tissue and get activated, they become the major source of inflammatory molecules and continue to attract more macrophages to further amplify the harmful cycle. The prototype monocyte chemotactic factor, MCP-1, has been under intensive investigation as such a candidate for recruiting macrophages into adipose tissue in obesity since its expression is upregulated in adipose tissue in early stage of diet-induced obesity. However, controversial results have been reported for the role of MCP-1. One publication showed that mice deficient in MCP-1 have partially reduced adipose tissue macrophage accumulation upon high fat diet and are accompanied with improved insulin sensitivity and hepatic steatosis (Kanda et al 2006). Acute expression of a dominant-negative MCP-1 mutant also ameliorated insulin resistance in both diet-induced obese mice and $d b / d b$ mice (Kanda et al 2006). Another publication demonstrated no change of adipose macrophage content in MCP-1 knock out mice (Inouye et al 2007). These results suggest the roles of other monocyte chemotactic factors. Nevertheless, reports from two independent laboratories reported that mice overexpressing MCP-1 transgene in adipose tissue under the promoter of adipocyte fatty acid binding protein have increased macrophage accumulation in adipose tissue and are insulin resistant (Kamei et al 2006; Kanda et al 2006). The major receptor of MCP-1 is CCR2, which also mediates signaling of other monocyte chemotactic factors such as MCP-2 and MCP-3. Macrophages recruited into adipose tissue in obese state have increased expression of CCR2. Mice deficient in CCR2 have a lean phenotype when fed on a high fat diet due to reduced food intake. When high fat-diet fed CCR2 deficient mice and control mice are matched for adiposity, partially decreased adipose macrophage content was observed. These mice have improved inflammatory profile in adipose tissue, along with improved systemic insulin sensitivity and ameliorated hepatic steatosis (Weisberg et al 2006). DIO mice treated with CCR 2 antagonist have a $28 \%$ reduction of adipose macrophage content and have improved hyperglycemia (Weisberg et al 2006). These data suggest that CCR2 plays a role in adipose tissue macrophage recruitment in obese state and also point out the potential role(s) of other chemokine receptor(s) since absence of CCR 2 only partially blocked macrophage infiltration upon high fat diet.

Macrophages are phagocytic cells that clear pathogens, dead cells and cell debris in innate immunity and wound healing. It has been shown that adipocyte death increases significantly in obese humans and mice via the mechanism of necrosis. The majority of infiltrated macrophages in adipose tissue are localized around dead adipocytes to form crownlike structure (CLS) (Cinti et al 2005). This scenario highly resembles atherosclerosis, which is caused by macrophage infiltration into aorta to clean excessive cholesterol and subsequent formation of foam cells. Interestingly, frequency of adipocyte death in epidydimal fat pat correlates with 
the extent of macrophage infiltration (Strissel et al 2007). These data indicate that infiltrated macrophages are involved in clearance of cell debris, leaked lipids and perhaps are important for adipose tissue remodeling. Macrophages are heterogeneous in function and their properties and activation state are dependent upon local environment factors. Two polarization states, M1 or "classically activated" and M2 or "alternatively activated", have been defined for macrophage activation. M1 macrophages have high proinflammatory cytokine expression and produce reactive oxygen species; M2 macrophages express high levels of anti-inflammatory cytokines, such as IL-10. IL-10 can selectively inhibit transcription rates of inflammatory gene and activate STAT3 to attenuate inflammatory signals induced by TNF $\alpha$. Macrophages infiltrated into adipose tissue in obese state possess features of M1 macrophages and more importantly, macrophages in CLS express protein of TNF $\alpha$ and IL-6 (Lumeng et al 2007; Strissel et al 2007). In contrast, resident macrophages in adipose tissue of lean mice have many features of M2 macrophages, including expression of M2 macrophage characteristic genes such as Ym1, arginase 1, and IL-10. High fat diet is sufficient to promote macrophage phenotypic switch from anti-inflammatory M2 polarization to proinflammatory M1 polarization. Peroxisome proliferator activated receptor- $\gamma(\operatorname{PPAR} \gamma)$, the molecular target for the anti-diabetic thiazolidinedione class of compounds, has been reported to play a key role in maturation of alternatively activated macrophages with anti-inflammatory properties (Bouhlel et al 2007). Mice deficient of PPAR $\gamma$ in myeloid cells have impaired activation of M2 macrophages, as demonstrated by decreased expression and activity of arginase, hallmarks of alternatively activated macrophages (Hevener et al 2007; Odegaard et al 2007). These mice have lower content of alternatively activated macrophages, increased local inflammation in adipose tissue, impaired insulin signaling in adipose tissue, muscle, and liver on chow diet. These mice are also prone to the development of obesity-related insulin resistance. These results indicate that phenotypic switch from M2 to M1 macrophages are critical for impairing insulin sensitivity.

Transient neutrophil infiltration into adipose tissue in obesity is also reported, which occurs 3 and 7 days upon high fat diet in epididymal but not subcutaneous fat and disappears on all subsequent times points (Elgazar-Carmon et al 2008). A potential chemotactic factor for neutrophil infiltration has been proposed to be IL-8, which can be secreted by adipose tissue in obesity. Neutrophils have been demonstrated to directly adhere to adipocytes and this process can be influenced by cations and activation state of neutrophils. The time course of adipose tissue neutrophil infiltration precedes macrophage infiltration, which does not start increase till 8 weeks upon high fat diet (Strissel et al 2007). Neutrophil infiltration reflects acute inflammation while macrophage infiltration symbols chronic inflammation. Activated neutrophils can release ROS and TNF $\alpha$, whether infiltrated neutrophils contribute to adipose inflammation remains a question to be studied.

\section{Targeting inflammation as a potential therapeutic approach for improving insulin sensitivity}

The findings for a potential role of adipose inflammation in the development of insulin resistance from animal models can also be extended to humans. Macrophage accumulation has been observed in human adipose tissue and the extent has strong positive correlation with BMI and adipocyte area but negatively related to insulin sensitivity (Weisberg et al 2003). The macrophage content is depot dependent. Omental fat of obese humans contains more macrophages than subcutaneous fat. Omental fat macrophage infiltration correlates to fasting glucose, insulin and hepatic fibroinflammatory lesions in obese patients (Cancello et al 2006). In addition, obese subjects with impaired glucose homeostasis have preferential omental adipose macrophage infiltration (Harman-Boehm et al 2007). Weight loss in obese subjects either through low calorie diet or bariatric surgery have decreased expression of inflammatory factors and increased expression of anti-inflammatory molecules, accompanied with decreased macrophage number and improved metabolic profile (Clement et al 2004; Cancello et al 2005). These data suggest that anti-inflammatory reagents or blockage of macrophage infiltration into adipose tissue may be beneficial for improving systemic insulin resistance in obese patients.

Inflammation has been generally correlated with insulin resistance in many situations, such as trauma, burn and infection. Although it is a relatively recent finding that adipose inflammation is associated with obesity-related insulin resistance, the effect of anti-inflammation reagent sodium salicylate on improving symptoms of diabetes mellitus was demonstrated a century ago (Williamson 1901). Later on, high dose aspirin was discovered to not only improve arthritis in a diabetic patient, but also make daily insulin injection unnecessary for controlling blood glucose level (Reid et al 1957). Cessation of aspirin upon disappearance of joint symptoms caused recurrence of glucose intolerance. Subsequent clinical trial with high dose-aspirin reconfirmed the 
effect on lowering blood glucose levels (Hecht and Goldner 1959). The molecular target mediating the hypoglycemic effect of salicylates has now been identified, which is IKK $\beta$ (Yuan et al 2001). IKK $\beta$ activates NF- $\kappa B$, which is a master transcription factor that activates transcription of numerous inflammatory genes. Potent small molecule inhibitor aginst IKK $\beta$ may be beneficial for improving insulin reistance in obese subjects.

Another line of evidence that repression of inflammation may be useful for controlling hyperglycemia in type 2 diabetic patients derives from the anti-inflammatory effect of the widely used insulin sensitizer. Thiazolidinediones (including rosiglitazone and pioglitazone), a new and highly efficacious class of insulin-sensitizing drugs that mainly targeting adipose tissue by activating PPAR $\gamma$, have been reported to have anti-inflammatory effect. PPAR $\gamma$ is a ligand-dependent nuclear hormone receptor predominantly expressed in adipocyte and is a master regulator of adipocyte differentiation. Expression of PPAR $\gamma$ is significantly increased upon macrophage activation and treatment with thiazolidinediones inhibits production of monocyte inflammatory cytokines and expression of iNOS, gelatinase B and scavenger genes, partly through repressing the activities of transcription factors AP-1, STAT, and NF- $\mathrm{BB}$. In animal models, PPAR $\gamma$ agonists have been reported to improve development of atherosclerosis (Li et al 2000; Stojanovska et al 2007). These results indicate that thiazolidinediones can repress macrophage-mediated inflammation. Interestingly, atherosclerosis-prone apolipoprotein E-deficient mice transplanted with inflamed visceral fat developed significantly more atherosclerosis compared to sham-operated animals. Treatment with pioglitazone decreased macrophage content of the transplanted visceral fat tissue, reduced plasma MCP-1 and reduced atherosclerosis (Ohman et al 2008). Ten-week treatment with pioglitazone in subjects with impaired glucose tolerance reduced macrophage number in adipose tissue and decreased inflammatory cytokine production (Di Gregorio et al 2005). Furthermore, thiazolidinediones are also reported to suppress NF- $\kappa \mathrm{B}$ activity in inflamed circulating MNCs in obese subjects (Ghanim et al 2001, 2006; Mohanty et al 2004). These results suggest that the insulin sensitizing effect of thiazolidinediones could be partially achieved through repression of adipose tissue macrophage content and subsequent reduction of inflammatory factor production.

In summary, substantive evidence derived from both animal models and human studies supports an important role of adipose inflammation in the development of obesityrelated insulin resistance. Development of new therapeutic agents targeting improving adipose inflammation, such as blocking macrophage infiltration and preventing phenotypic switch of M2 to M1 macrophages, may be effective for attenuating insulin resistance and hyperglycemia associated with obesity.

\section{Disclosure}

The authors report no conflicts of interest in this work.

\section{References}

Arkan MC, Hevener AL, Greten FR, et al. 2005. IKK-beta links inflammation to obesity-induced insulin resistance. Nat Med, 11:191-8.

Bluher M, Michael MD, Peroni OD, et al. 2002. Adipose tissue selective insulin receptor knockout protects against obesity and obesity-related glucose intolerance. Dev Cell, 3:25-38.

Bouhlel MA, Derudas B, Rigamonti E, et al. 2007. PPARgamma activation primes human monocytes into alternative M2 macrophages with antiinflammatory properties. Cell Metab, 6:137-43.

Cai D, Yuan M, Frantz DF, et al. 2005. Local and systemic insulin resistance resulting from hepatic activation of IKK-beta and NF-kappaB. Nat Med, 11:183-90.

Cancello R, Henegar C, Viguerie N, et al. 2005. Reduction of macrophage infiltration and chemoattractant gene expression changes in white adipose tissue of morbidly obese subjects after surgery-induced weight loss. Diabetes, 54:2277-86.

Cancello R, Tordjman J, Poitou C, et al. 2006. Increased infiltration of macrophages in omental adipose tissue is associated with marked hepatic lesions in morbid human obesity. Diabetes, 55:1554-61.

Charriere G, Cousin B, Arnaud E, et al. 2003. Preadipocyte conversion to macrophage. Evidence of plasticity. J Biol Chem, 278:9850-5.

Cinti S, Mitchell G, Barbatelli G, et al. 2005. Adipocyte death defines macrophage localization and function in adipose tissue of obese mice and humans. J Lipid Res, 46:2347-55.

Clement K, Viguerie N, Poitou C, et al. 2004. Weight loss regulates inflammation-related genes in white adipose tissue of obese subjects. FASEB J, 18:1657-69.

Cousin B, Munoz O, Andre M, et al. 1999. A role for preadipocytes as macrophage-like cells. FASEB J, 13:305-12.

Crook MA, Tutt P, Simpson H, et al. 1993. Serum sialic acid and acute phase proteins in type 1 and type 2 diabetes mellitus. Clin Chim Acta, 219:131-8.

Di Gregorio GB, Yao-Borengasser A, Rasouli N, et al. 2005. Expression of CD68 and macrophage chemoattractant protein-1 genes in human adipose and muscle tissues: association with cytokine expression, insulin resistance, and reduction by pioglitazone. Diabetes, 54:2305-13.

Elgazar-Carmon V, Rudich A, Hadad N, et al. 2008. Neutrophils transiently infiltrate intra-abdominal fat early in the course of high fat feeding. J Lipid Res, 49:1894-903.

Fearnley GR, Vincent CT, Chakrabarti R. 1959. Reduction of blood fibrinolytic activity in diabetes mellitus by insulin. Lancet, 2:1067.

Feinstein R, Kanety H, Papa MZ, et al.1993. Tumor necrosis factor-alpha suppresses insulin-induced tyrosine phosphorylation of insulin receptor and its substrates. J Biol Chem, 268:26055-8.

Festa A, D'Agostino R Jr, Tracy RP, et al. 2002. Elevated levels of acutephase proteins and plasminogen activator inhibitor-1 predict the development of type 2 diabetes: the insulin resistance atherosclerosis study. Diabetes, 51:1131-7.

Ganrot PO, Gydell K, Ekelund H. 1967. Serum concentration of alpha-2macroglobulin, haptoglobin and alpha-1-antitrypsin in diabetes mellitus. Acta Endocrinol (Copenh), 55:537-44.

Gerhardt CC, Romero IA, Cancello R, et al. 2001. Chemokines control fat accumulation and leptin secretion by cultured human adipocytes. Mol Cell Endocrinol, 175:81-92. 
Ghanim H, Aljada A, Hofmeyer D, et al. 2004. Circulating mononuclear cells in the obese are in a proinflammatory state. Circulation, 110:1564-71.

Ghanim H, Dhindsa S, Aljada A, et al. 2006. Low-dose rosiglitazone exerts an antiinflammatory effect with an increase in adiponectin independently of free fatty acid fall and insulin sensitization in obese type 2 diabetics. J Clin Endocrinol Metab, 91:3553-8.

Ghanim H, Garg R, Aljada A, et al. 2001. Suppression of nuclear factorkappaB and stimulation of inhibitor kappaB by troglitazone: evidence for an anti-inflammatory effect and a potential antiatherosclerotic effect in the obese. J Clin Endocrinol Metab, 86:1306-12.

Green A, Dobias SB, Walters DJ, et al. 1994. Tumor necrosis factor increases the rate of lipolysis in primary cultures of adipocytes without altering levels of hormone-sensitive lipase. Endocrinology, 134:2581-8.

Harman-Boehm I, Bluher M, Redel H, et al. 2007. Macrophage infiltration into omental versus subcutaneous fat across different populations: effect of regional adiposity and the comorbidities of obesity. $J$ Clin Endocrinol Metab, 92:2240-7.

Hecht A, Goldner MG. 1959. Reappraisal of the hypoglycemic action of acetylsalicylate. Metabolism, 8:418-28.

Hevener AL, Olefsky JM, Reichart D, et al. 2007. Macrophage PPAR gamma is required for normal skeletal muscle and hepatic insulin sensitivity and full antidiabetic effects of thiazolidinediones. $J$ Clin Invest, 117:1658-69.

Hill JO, Wyatt HR, Reed GW, et al. 2003. Obesity and the environment: where do we go from here? Science, 299:853-5.

Hirosumi J, Tuncman G, Chang L, et al. 2002. A central role for JNK in obesity and insulin resistance. Nature, 420:333-6.

Hotamisligil GS, Arner P, Caro JF, et al. 1995. Increased adipose tissue expression of tumor necrosis factor-alpha in human obesity and insulin resistance. J Clin Invest, 95:2409-15.

Hotamisligil GS, Budavari A, Murray D, et al. 1994. Reduced tyrosine kinase activity of the insulin receptor in obesity-diabetes. Central role of tumor necrosis factor-alpha. J Clin Invest, 94:1543-9.

Hotamisligil GS, Shargill NS, Spiegelman BM. 1993. Adipose expression of tumor necrosis factor-alpha: direct role in obesity-linked insulin resistance. Science, 259:87-91.

Inouye KE, Shi H, Howard JK, et al. 2007. Absence of CC chemokine ligand 2 does not limit obesity-associated infiltration of macrophages into adipose tissue. Diabetes, 56:2242-50.

Kamei N, Tobe K, Suzuki R, et al. 2006. Overexpression of monocyte chemoattractant protein-1 in adipose tissues causes macrophage recruitment and insulin resistance. J Biol Chem, 281:26602-14.

Kanda H, Tateya S, Tamori Y, et al. 2006. MCP-1 contributes to macrophage infiltration into adipose tissue, insulin resistance, and hepatic steatosis in obesity. $J$ Clin Invest, 116:1494-505.

Kopelman PG. 2000. Obesity as a medical problem. Nature, 404:635-43.

Lee JY, Sohn KH, Rhee SH, et al. 2001. Saturated fatty acids, but not unsaturated fatty acids, induce the expression of cyclooxygenase- 2 mediated through Toll-like receptor 4. J Biol Chem, 276:16683-9.

Li AC, Brown KK, Silvestre MJ, et al. 2000. Peroxisome proliferatoractivated receptor gamma ligands inhibit development of atherosclerosis in LDL receptor-deficient mice. J Clin Invest, 106:523-31.

Lumeng CN, Bodzin JL, Saltiel AR. 2007. Obesity induces a phenotypic switch in adipose tissue macrophage polarization. J Clin Invest, 117:175-84.

Medzhitov R, Preston-Hurlburt P, Janeway CA Jr. 1997. A human homologue of the Drosophila Toll protein signals activation of adaptive immunity. Nature, 388:394-7.

Mohanty P, Aljada A, Ghanim H, et al. 2004. Evidence for a potent antiinflammatory effect of rosiglitazone. J Clin Endocrinol Metab, 89:2728-35.

Morimoto Y, Nishikawa K, Ohashi M. 1997. KB-R7785, a novel matrix metalloproteinase inhibitor, exerts its antidiabetic effect by inhibiting tumor necrosis factor-alpha production. Life Sci, 61:795-803.

Odegaard JI, Ricardo-Gonzalez RR, Goforth MH, et al. 2007. Macrophagespecific PPARgamma controls alternative activation and improves insulin resistance. Nature, 447:1116-20.

Ogston D, McAndrew GM. 1964. Fibrinolysis in obesity. Lancet, $2: 1205-7$.
Ohman MK, Shen Y, Obimba CI, et al. 2008. Visceral adipose tissue inflammation accelerates atherosclerosis in apolipoprotein E-deficient mice. Circulation, 117:798-805.

Pickup JC, Mattock MB, Chusney GD, et al. 1997. NIDDM as a disease of the innate immune system: association of acute-phase reactants and interleukin-6 with metabolic syndrome X. Diabetologia, 40:1286-92.

Poltorak A, He X, Smirnova I, et al. 1998. Defective LPS signaling in $\mathrm{C} 3 \mathrm{H} / \mathrm{HeJ}$ and $\mathrm{C} 57 \mathrm{BL} / 10 \mathrm{ScCr}$ mice: mutations in Tlr4 gene. Science, 282:2085-8.

Pradhan AD, Manson JE, Rifai N, et al. 2001. C-reactive protein, interleukin 6, and risk of developing type 2 diabetes mellitus. JAMA, 286:327-34.

Reid J, MacDougall AI, Andrews MM. 1957. Aspirin and diabetes mellitus. Br Med J, 2:1071-4.

Rotter V, Nagaev I, Smith U. 2003. Interleukin-6 (IL-6) induces insulin resistance in 3T3-L1 adipocytes and is, like IL-8 and tumor necrosis factor-alpha, overexpressed in human fat cells from insulin-resistant subjects. J Biol Chem, 278:45777-84.

Sartipy P, Loskutoff DJ. 2003. Monocyte chemoattractant protein 1 in obesity and insulin resistance. Proc Natl Acad Sci U S A, 100:7265-70.

Schreyer SA, Chua SC Jr, LeBoeuf RC. 1998. Obesity and diabetes in TNF-alpha receptor- deficient mice. J Clin Invest, 102:402-11.

Shi H, Kokoeva MV, Inouye K, et al. 2006. TLR4 links innate immunity and fatty acid-induced insulin resistance. J Clin Invest, 116:3015-25.

Stojanovska L, Honisett SY, Komesaroff PA. 2007. The anti-atherogenic effects of thiazolidinediones. Curr Diabetes Rev, 3:67-74.

Strissel KJ, Stancheva Z, Miyoshi H, et al. 2007. Adipocyte death, adipose tissue remodeling, and obesity complications. Diabetes, 56:2910-8.

Tsukumo DM, Carvalho-Filho MA, Carvalheira JB, et al. 2007. Loss-offunction mutation in Toll-like receptor 4 prevents diet-induced obesity and insulin resistance. Diabetes, 56:1986-98.

Uysal KT, Wiesbrock SM, Hotamisligil GS. 1998. Functional analysis of tumor necrosis factor (TNF) receptors in TNF-alpha-mediated insulin resistance in genetic obesity. Endocrinology, 139:4832-8.

Uysal KT, Wiesbrock SM, Marino MW, et al. 1997. Protection from obesity-induced insulin resistance in mice lacking TNF-alpha function. Nature, 389:610-4.

Ventre J, Doebber T, Wu M, et al. 1997. Targeted disruption of the tumor necrosis factor-alpha gene: metabolic consequences in obese and nonobese mice. Diabetes, 46:1526-31.

Vozarova B, Weyer C, Lindsay RS, et al. 2002. High white blood cell count is associated with a worsening of insulin sensitivity and predicts the development of type 2 diabetes. Diabetes, 51:455-61.

Weisberg SP, Hunter D, Huber R, et al. 2006. CCR2 modulates inflammatory and metabolic effects of high-fat feeding. $J$ Clin Invest, 116:115-24.

Weisberg SP, McCann D, Desai M, et al. 2003. Obesity is associated with macrophage accumulation in adipose tissue. $J$ Clin Invest, 112:1796-808.

Williamson RT. 1901. On the treatment of glycosuria and diabetes mellitus with sodium salicylate. $\mathrm{Br}$ Med $J, 1: 760-2$.

Xu H, Barnes GT, Yang Q, et al. 2003. Chronic inflammation in fat plays a crucial role in the development of obesity-related insulin resistance. J Clin Invest, 112:1821-30.

$\mathrm{Xu} \mathrm{H}$, Hirosumi J, Uysal KT, et al. 2002a. Exclusive action of transmembrane $\mathrm{TNF}$ alpha in adipose tissue leads to reduced adipose mass and local but not systemic insulin resistance. Endocrinology, 143:1502-11.

$\mathrm{Xu} \mathrm{H,} \mathrm{Hotamisligil} \mathrm{GS.} \mathrm{2001.} \mathrm{Signaling} \mathrm{pathways} \mathrm{utilized} \mathrm{by} \mathrm{tumor} \mathrm{necrosis}$ factor receptor 1 in adipocytes to suppress differentiation. FEBS Lett, 506:97-102.

Xu H, Sethi JK, Hotamisligil GS. 1999. Transmembrane tumor necrosis factor (TNF)-alpha inhibits adipocyte differentiation by selectively activating TNF receptor 1. J Biol Chem, 274:26287-95.

Xu H, Uysal KT, Becherer JD, et al. 2002b. Altered tumor necrosis factoralpha (TNF-alpha) processing in adipocytes and increased expression of transmembrane TNF-alpha in obesity. Diabetes, 51:1876-83.

Yuan M, Konstantopoulos N, Lee J, et al. 2001. Reversal of obesity- and diet-induced insulin resistance with salicylates or targeted disruption of Ikkbeta. Science, 293:1673-7. 
